\title{
Force-perturbation analysis of recent thinning and acceleration of Jakobshavn Isbræ, Greenland
}

\author{
RoBert H. THOMAS, ${ }^{1,2}$ \\ ${ }^{1}$ EG $\mathcal{E}$ G Services, NASA Wallops Flight Facility, Building N-159, Wallops Island,Virginia 23337, U.S.A. \\ ${ }^{2}$ Centro de Estudios Cientificos (CECS), Avenido Arturo Prat 514, Valdivia, Chile \\ E-mail: thomas@osb.wff.nasa.gov
}

\begin{abstract}
Observations between 1997 and 2001, of a 30\% velocity increase and up to $60 \mathrm{~m}$ thinning of downstream parts of Jakobshavn Isbræ, Greenland, immediately following calving of about $4 \mathrm{~km}$ of its $15 \mathrm{~km}$ floating ice tongue, suggest that acceleration may have been initiated by the calving. Assuming that the force perturbation associated with such weakening is swiftly transmitted far up-glacier, I develop equations to estimate the perturbation. Initially, the observed changes are consistent with the comparatively small perturbation associated with the calving. Thereafter, it was probably sustained by thinning of the remaining ice tongue at rates of about $80 \mathrm{~m} \mathrm{a}^{-1}$. Otherwise, the force perturbation would soon have been balanced by reduction in the hydrostatic driving force for longitudinal creep as the glacier thinned, with velocities dropping to their former values. The calculated force perturbation increases to a maximum about $10 \mathrm{~km}$ inland of the grounding line, consistent with decreasing weight forces as the glacier thins over bedrock that slopes uphill seawards. Further inland, it progressively decreases, probably because marginal drag increased as the glacier accelerated. Both here and on the floating tongue, marginal ice appears to have been softened by the influence of locally intense shear on ice temperature and/or fabric. More recent observations show continued acceleration and thinning, and most of the remaining ice tongue calved away in April 2003, so thinning is likely to continue.
\end{abstract}

\section{INTRODUGTION}

Draining approximately $7 \%$ of the ice sheet, with a total annual snow accumulation equivalent to almost $30 \mathrm{~km}^{3}$ of ice, Jakobshavn Isbræ is the most active glacier in Greenland. The calving front retreated $30 \mathrm{~km}$ between 1850 and 1964 but it has occupied approximately the same location since (Weidick, 1995; Sohn and others, 1998). Balance calculations by Echelmeyer and others (1992) suggest that total loss by surface and basal melt and ice discharge was slightly less than total accumulation within the drainage basin. Airborne laser-altimeter surveys along a $120 \mathrm{~km}$ profile in the Jakobshavn ice-drainage basin have been made almost every year since 1991 by NASA's Airborne Topographic Mapper (ATM). These, together with results from other survey lines over the glacier, show slow sporadic thickening between 1991 and 1997 (Fig. 1), in broad agreement with the balance calculations. Since 1997, however, there has been sustained thinning of several $\mathrm{m} \mathrm{a}^{-1}$ within $20 \mathrm{~km}$ of the grounding line, with lower rates of thinning further inland (Thomas and others, 2003). Estimates of anomalous melting using positive-degree-day methods are small compared to total thinning, indicating that much of the thinning is dynamic, associated with increased longitudinal creep rates and therefore velocity.

At elevations up to at least $1000 \mathrm{~m}$, thinning rates were substantially larger during 1999-2001 than during the previous 2 years, with total thinning over the entire 4 years by $>40 \mathrm{~m}$ below $500 \mathrm{~m}$ elevation (Fig. 1). The ATM surveys in 2002 and 2003 show continued, widespread thinning over most of the glacier basin, reaching rates of $>10 \mathrm{~m} \mathrm{a}^{-1}$ for much of the fast-moving main trunk of the glacier. Although velocity measurements for various periods since the 1960s showed little variation (Carbonnell and Bauer, 1968; Lingle and others, 1981; Echelmeyer and Harrison, 1990; Fastook and others, 1995; Abdalati and Krabill, 1999), such rapid dynamic thinning implies a recent substantial velocity increase. This was confirmed by a series of Landsat images from 2001 and 2002 showing velocities increasing about $30 \%$, from $7 \mathrm{~km} \mathrm{a}^{-1}$ in 1997 (Abdalati and Krabill, 1999) to $>9 \mathrm{~km} \mathrm{a}^{-1}$ in 2001, with a further increase by 2002. The more recent results form part of the overall NASA investigation of the glacier and have not yet been published; they are included here by kind permission of W. Krabill, who directs the ATM surveys, and W. Abdalati, who provided me with early velocity estimates from the Landsat images.

Until recently, Jakobshavn Isbræ terminated in a floating ice tongue, about $15 \mathrm{~km}$ long, between fjord walls $6-$ $7 \mathrm{~km}$ apart (Fig. 1). The ATM surveys showed rapid lowering of surface elevations for this floating ice, equivalent to a total thinning by $>300 \mathrm{~m}$ between 1997 and 2001, assuming the ice to be in hydrostatic equilibrium (Thomas and others, 2003). This is far larger than thinning of grounded portions of the glacier immediately upstream, and is difficult to explain without invoking an increase in basal melting rates. Moreover, between 1997 and 1998, the calving ice front retreated by about $4 \mathrm{~km}$. Consequently, it is quite possible that the transition from slow thickening to rapid thinning on Jakobshavn Isbræ was initiated by calving and accelerated melting from its floating ice tongue, which thinned suffi- 

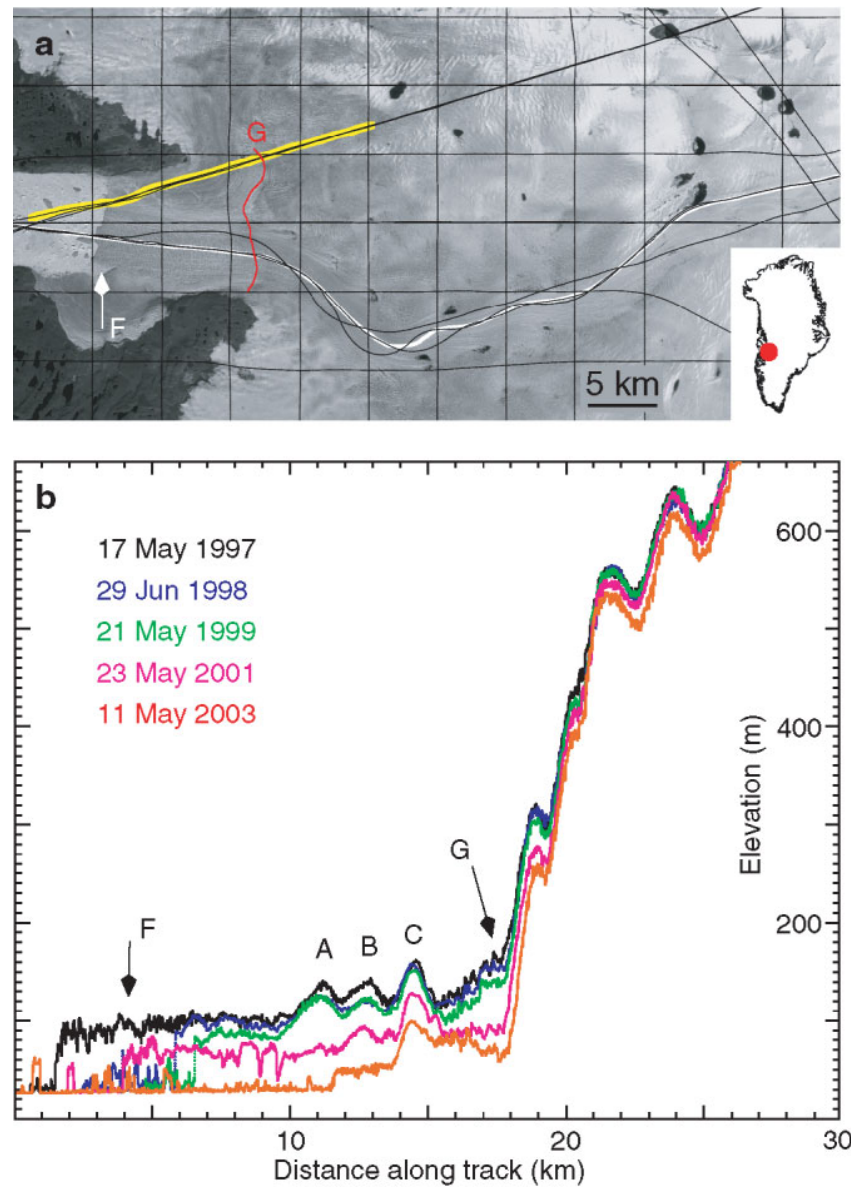

Fig. 1. (a) ATM flight tracks along the northern and southern branches of Jakobshavn Isbre, superimposed on a Landsat image from Fuly 2001. Surveys were made along the northern branch almost every year since 1991, and the sequence of elevation profiles ( $b$ ), along the yellow track in $(a)$, shows progressive thinning since 1997, extending from the ice front to $600 \mathrm{~m}$ elevation (Thomas and others, 2003). Thinning along the main southern branch of the glacier, measured at locations where a grid network of survey lines flown in 1997 were crossed by later surveys, are similar to those shown here. The probable grounding-line location $(G)$ is at the transition from higher-elevation, rugged topography to lower, near-horizontal surfaces, and possible locally grounded ice rumples $(A-C)$ are identified where hills persist from year to year. The calving ice front is marked by an abrupt drop in surface elevation to about $30 \mathrm{~m}$ (the height of sea level above the ellipsoid). F marks its location in 2001. It retreated about $4 \mathrm{~km}$ between 1997 and 1998, readvanced $2 \mathrm{~km}$ by 2001, and most of the remaining floating ice tongue had calved away by 2003.

ciently to become unpinned from shoaling seabed beneath grounded ice rumples (Thomas and others, 2003). If so, this suggests the need to reconsider the concept of marine icesheet instability, first proposed 30 years ago by Hughes (1972) and Weertman (1974). This involves rapid collapse of portions of an ice sheet that rest on rock well below sea level. The cause for collapse is weakening of ice shelves that limit outflow from marine ice sheets, and an associated increase in longitudinal tensile stresses, and hence creep rates and discharge speeds, far into the interior of the ice sheet. This concept is based on an implicit assumption that stress perturbations can be transmitted far upstream, and that longitudinal stretching of much of the grounded ice sheet is governed by dynamics very similar to those of an ice shelf.
The viability of this mechanism has been widely disputed (e.g. Hindmarsh, 1993, 1996; Van der Veen, 2001), with the opposing school claiming that outlet-glacier behavior is determined almost totally by local conditions, such as bed and side shear stresses, rather than events occurring far downstream. Moreover, even if velocities were to increase for glaciers flowing into a weakening ice shelf, this should cause an increase in basal and marginal drag to balance any reduction in ice-shelf backforces, and increased advection of thicker ice from upstream would inhibit glacier thinning. However, the recent behavior of Jakobshavn Isbræ, of glaciers flowing into the Amundsen Sea, West Antarctica (Rignot and others, 2002; Shepherd and others, 2002), and of others that used to flow into recently collapsed portions of the Larsen Ice Shelf, West Antarctica (De Angelis and Skvarca, 2003), suggests that inland ice does swiftly respond to downstream changes. If so, the impact is not confined to marine portions of an ice sheet, and it applies to any perturbation, whether from a weakening ice shelf or from increased basal lubrication of the glacier. In the Appendix, I develop equations relating such force perturbations to changes in longitudinal strain rates (and therefore velocities), and here I apply them toJakobshavn Isbræ. First, however, I apply them to a simplified model glacier in order to examine the spatial distribution of creep-rate changes and resulting ice-thinning rates corresponding to a comparatively small reduction in resisting forces, and how these are affected by different glacier geometry. I use the following equations from the Appendix (equation numbers italicized), where their derivation is explained:

$$
\begin{aligned}
\Delta \varepsilon_{x} / \varepsilon_{x}= & k^{\prime}\left[\left(\varepsilon_{x} / k\right)^{1 / 3}+0.5 \rho_{\mathrm{i}} g \Delta H_{\mathrm{i}}-\Delta P\right]^{3} / \varepsilon_{x}-1 \\
\partial H_{\mathrm{i}} / \partial t \sim & \Delta A-(1+\alpha)\left(H _ { \mathrm { i } } \left\{k ^ { \prime } \left[\left(\varepsilon_{x} / k\right)^{1 / 3}\right.\right.\right. \\
& \left.\left.\left.+0.5 \rho_{\mathrm{i}} g \Delta H_{\mathrm{i}}-\Delta P\right]^{3}-\varepsilon_{x}\right\}+\varepsilon_{x} \Delta H_{\mathrm{i}}\right) \\
& -H_{\mathrm{i}} \varepsilon_{x} \Delta \alpha-V \Delta\left(\partial H_{\mathrm{i}} / \partial x\right)-\Delta V \partial H_{\mathrm{i}} / \partial x,
\end{aligned}
$$

where $\varepsilon_{x}$ is the longitudinal strain rate, $\rho_{\mathrm{i}}$ is ice density, $g$ is acceleration due to gravity, $V$ is velocity, $A$ is surface accumulation rate expressed as a depth/unit time, $\Delta$ refers to changes following a perturbation, $\Delta P$, in back pressure, assumed to be constant in the $y$ direction across glacier width $W$ and thickness $H_{\mathrm{i}}$, and primed values refer to conditions after the perturbation. $k=\theta / B^{3}$ with $B$ the ice stiffness parameter, $\theta=\left(1+\alpha+\alpha^{2}\right) /(2+\alpha)^{3}$, and $\alpha=\varepsilon_{y} / \varepsilon_{x}$.

\section{MODEL GLACIER}

The model glacier is a highly simplified version of Jakobshavn Isbræ, comprising a high-elevation catchment region of width $W=250 \mathrm{~km}$, where flow is approximately parallel for distance along glacier from $x=0$ to $200 \mathrm{~km}(\alpha \sim 0)$, and thickness $H_{\mathrm{i}}$ decreases from 3000 to $2600 \mathrm{~m}$. The basin then progressively converges from $x=200 \mathrm{~km}$ to $x=400 \mathrm{~km}$ where $W=200 \mathrm{~km}$, with $H_{\mathrm{i}}$ decreasing from 2500 to $2200 \mathrm{~m}$, followed by a region of increased convergence and more rapid flow for $50 \mathrm{~km}$ with $W$ decreasing to $10 \mathrm{~km}$ and $H_{i}$ decreasing to $2000 \mathrm{~m}$. Finally, the glacier is channeled into a narrow trough for the final $40 \mathrm{~km}$, converging to $W=6 \mathrm{~km}$ and thinning to $H=1000 \mathrm{~m}$ at the grounding line, where it flows into a floating tongue within a fjord of 
Table 1. Estimates for a model glacier of fractional increases in strain rate $\left(\Delta \varepsilon_{x} / \varepsilon_{x}\right)$, ice velocity $(\Delta V / V)$ and of thinning rate $\left(\partial H_{\mathrm{i}} / \partial t\right)$ for a force perturbation of $-300 \mathrm{GN}$. Thinning rates are shown before correction for advection increase, $\left(\partial H_{\mathrm{i}} / \partial t\right)_{\mathrm{d}}$ and after correction $\left(\partial H_{\mathrm{i}} / \partial t\right)_{\mathrm{c}}$

\begin{tabular}{|c|c|c|c|c|c|c|c|c|c|c|c|}
\hline$x$ & $W$ & $H_{\mathrm{i}}$ & $V$ & $\partial H_{\mathrm{i}} / \partial x$ & $B$ & $\alpha$ & $A$ & $\Delta \varepsilon_{x} / \varepsilon_{x}$ & $\Delta V / V$ & $\left(\partial H_{\mathrm{i}} / \partial t\right)_{\mathrm{d}}$ & $\left(\partial H_{\mathrm{i}} / \partial t\right)_{\mathrm{c}}$ \\
\hline $\mathrm{km}$ & $\mathrm{km}$ & $\mathrm{m}$ & $\mathrm{ma}^{-1}$ & $10^{-3}$ & $\mathrm{kPa}^{1 / 3}$ & & $\mathrm{ma}^{-1}$ & $\%$ & $\%$ & $\mathrm{ma}^{-1}$ & $\mathrm{ma}^{-1}$ \\
\hline 0 & 250 & 3000 & 0 & -2 & 600 & 0 & 0.3 & 2.2 & 0 & -0.007 & -0.007 \\
\hline 100 & 250 & 2800 & 11 & -2 & 600 & 0 & 0.3 & 2.2 & 2.3 & -0.007 & -0.007 \\
\hline 200 & 250 & 2600 & 23 & -2 & 600 & 0 & 0.3 & 2.3 & 2.3 & -0.008 & -0.007 \\
\hline 200 & 250 & 2600 & 23 & -2 & 600 & -0.29 & 0.3 & 2.2 & 2.3 & -0.008 & -0.007 \\
\hline 300 & 190 & 2400 & 47 & -2 & 600 & -0.48 & 0.3 & 2.9 & 2.5 & -0.012 & -0.009 \\
\hline 400 & 130 & 2200 & 92 & -2 & 600 & -0.66 & 0.3 & 4.2 & 3.3 & -0.020 & -0.014 \\
\hline 400 & 130 & 2200 & 92 & -4 & 600 & -0.87 & 0.3 & 3.6 & 3.3 & -0.020 & -0.007 \\
\hline 410 & 106 & 2160 & 116 & -4 & 580 & -0.94 & 0.04 & 4.5 & 3.6 & -0.017 & 0 \\
\hline 420 & 82 & 2120 & 151 & -4 & 560 & -0.97 & -0.22 & 5.5 & 4.1 & -0.014 & +0.011 \\
\hline 430 & 58 & 2080 & 215 & -4 & 540 & -0.99 & -0.48 & 6.7 & 4.9 & -0.017 & +0.026 \\
\hline 440 & 34 & 2040 & 369 & -4 & 520 & -0.99 & -0.74 & 8.5 & 6.5 & -0.058 & +0.038 \\
\hline 450 & 10 & 2000 & 1270 & -4 & 500 & -0.99 & -1 & 13.8 & 11.1 & -0.52 & +0.042 \\
\hline 460 & 9 & 1750 & 1604 & -25 & 475 & -0.45 & -1.8 & 22.2 & 12.9 & -8.4 & -3.2 \\
\hline 470 & 8 & 1500 & 2090 & -25 & 450 & -0.44 & -2.5 & 27.1 & 15.6 & -13 & -5 \\
\hline 475 & 7.5 & 1375 & 2421 & -25 & 438 & -0.44 & -2.9 & 30.3 & 17.3 & -17 & -7 \\
\hline 480 & 7 & 1250 & 2841 & -25 & 425 & -0.43 & -3.3 & 34.1 & 19.5 & -23 & -9 \\
\hline 485 & 6.5 & 1125 & 3383 & -25 & 413 & -0.42 & -3.6 & 38.7 & 22.2 & -31 & -12 \\
\hline 490 & 6 & 1000 & 4106 & -25 & 400 & -0.4 & -4 & 44 & 26 & -45 & -18 \\
\hline
\end{tabular}

width $6 \mathrm{~km}$. Accumulation rate $(A)$ is $0.3 \mathrm{~m} \mathrm{a}^{-1}$ over the two higher-elevation regions, with $A$ decreasing linearly from 0.3 to $-1 \mathrm{~m} \mathrm{a}^{-1}$ and then to $-4 \mathrm{~m} \mathrm{a}^{-1}$ within the two lower regions. Assuming that the glacier is initially in steady state, I applied the requirement for volume continuity to infer velocities and strain rates $\left(\varepsilon_{z}, \varepsilon_{y}\right.$ and $\left.\varepsilon_{x}\right)$ at various points along the glacier. The backforce at the grounding line is then changed by $\Delta F_{\mathrm{b}}=-300 \mathrm{GN}$, consistent with loss of small ice rumples or of part of its floating ice tongue (see Appendix), and resulting in a perturbation $\left(\Delta P \sim \Delta F_{\mathrm{b}} /\left(W H_{\mathrm{i}}\right)\right)$ in back pressure along the entire glacier. For comparison, the total hydrostatic force $\left(F_{\mathrm{h}} \cong 0.5 \rho_{\mathrm{i}} g W H_{\mathrm{i}}{ }^{2}\right)$ ranges between $10^{16} \mathrm{~N}$ at the upstream end of the glacier and $27000 \mathrm{GN}$ at the grounding line, with $\Delta P$ ranging from $0.4 \mathrm{kPa}$ upstream to $50 \mathrm{kPa}$ at the grounding line. Assuming no change in $B$ or in the ratio $(\alpha)$ between longitudinal and lateral strain rates (so that $k^{\prime}=k$ ), Equation $(A 10)$ becomes

$$
\Delta \varepsilon_{x} / \varepsilon_{x} \sim\left(\varepsilon_{x}^{1 / 3}-k^{1 / 3} \Delta P\right)^{3} / \varepsilon_{x}-1,
$$

for conditions immediately after the force perturbation $\left(\Delta H_{\mathrm{i}} \sim 0\right)$. This was solved using the estimated values of $\varepsilon_{x}$ and $\alpha\left(=\varepsilon_{y} / \varepsilon_{x}\right)$. Post-perturbation velocities were calculated assuming variation in $\left(\Delta \varepsilon_{x} / \varepsilon_{x}\right)$ is linear between points where it was calculated. Equation (A14) was simplified to give an indication of the thickness change during a short period after force perturbation:

$$
\left(\partial H_{\mathrm{i}} / \partial t\right)_{\mathrm{c}} \sim-(1+\alpha) H_{\mathrm{i}} \Delta \varepsilon_{x}-\Delta V \partial H_{\mathrm{i}} / \partial x
$$

with the first term on the righthand side representing the thickening $\left(\partial H_{\mathrm{i}} / \partial t\right)_{\mathrm{d}}$ caused solely by altered strain rates, and the second term representing the correction for changes in ice-thickness advection. Results are summarized in Table 1.

The assumed values of $B=600,500$ and $400 \mathrm{kPa}^{1 / 3}$ correspond to effective ice temperatures of about $-21^{\circ},-16^{\circ}$ and $-10^{\circ} \mathrm{C}$, with the ice warming at lower elevations partly because of downward percolation of surface meltwater and strain heating. Two estimates for $\Delta \varepsilon_{x} / \varepsilon_{x}$ and $\partial H_{\mathrm{i}} / \partial t$ are calculated at locations where there is a change in thickness, slope and glacier convergence. The large difference between estimates at $x=450 \mathrm{~km}$ is caused by large change in these parameters assumed at this location.

Over the first $400 \mathrm{~km}$ of the glacier, thinning rates are small, and would be submerged by the effects of short-term variability in accumulation and ablation rates (Van derVeen, 1993). Further seaward, correction for increased advection results in ice thickening rather than thinning. But, beyond $450 \mathrm{~km}$, creep thinning $\left(\partial H_{\mathrm{i}} / \partial t\right)_{\mathrm{d}}$ becomes so large that corrected thinning rates exceed $5 \mathrm{~m} \mathrm{a}^{-1}$ over the final $20 \mathrm{~km}$. Although these estimates take no account of changes in $\alpha$ as the longitudinal strain rates change, nor of increases in backforces if the increasing velocities result in an increase in basal and marginal drag, they are similar to thinning rates recently observed on Kangerdlugssuaq Gletscher, Greenland, and Jakobshavn Isbræ (Thomas and others, 2000, 2003). In the next section, I apply a similar analysis toJakobshavn Isbræ, in order to estimate the force perturbation consistent with observed glacier acceleration and thinning.

\section{JAKOBSHAVN ISBR $Æ$}

Assuming that the approximately $30 \%$ velocity increase observed between 1997 and 2001, described above, represents an equal increase in longitudinal strain rates within the lower reaches of the glacier, then $\Delta \varepsilon_{x} / \varepsilon_{x} \sim 0.30$. Within this region, Echelmeyer and Harrison (1990) measured velocities at several locations along the glacier, and ice thicknesses were measured by Clarke and Echelmeyer (1996). I interpolated between measured thicknesses, and to a grounding-line thickness inferred assuming hydrostatic equilibrium. I assume the width of the main active trunk of the glacier is $5 \mathrm{~km}$ for a distance $55 \mathrm{~km}$ upstream from the grounding line, and that $B=400 \mathrm{kPa}^{1 / 3}$. 

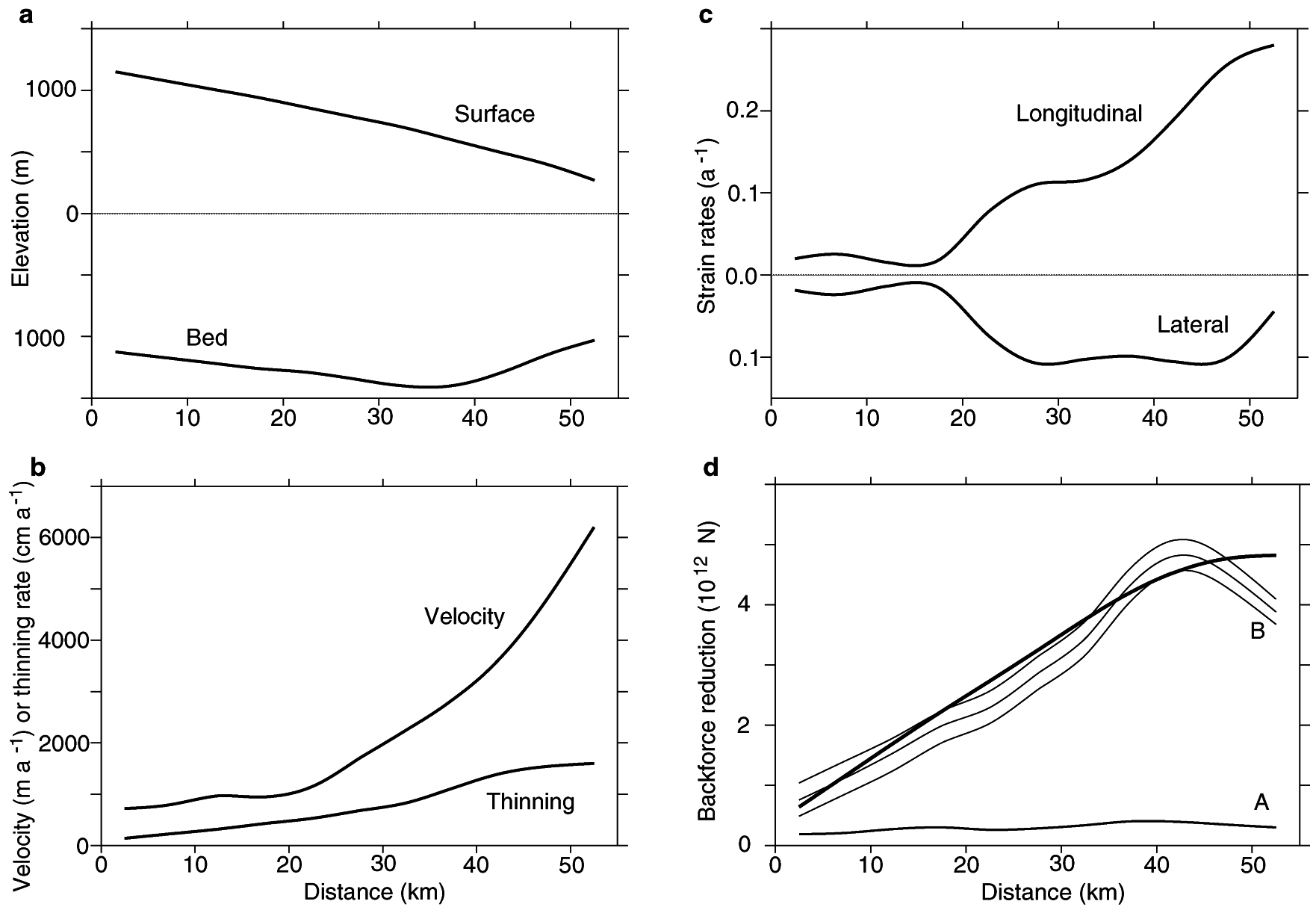

Fig. 2. Glacier profile for Jakobshavn Isbre (a), velocity and thinning rates ( $b$ ), strain rates (c) and estimated reduction in backforces $(d)$ corresponding to thinning and $\sim 30 \%$ velocity increase, observed between 1997 and 2001 . These data refer to flight-lines in Figure 1, along the main, southern branch of the glacier. The grounding line is at approximately $55 \mathrm{~km}$ along the profile. Curve A in (d) shows estimated backforce reduction immediately following an assumed instantaneous velocity increase, before the glacier has thinned. Curves B show the backforce reduction, and estimated error bounds, occurring between 1997 and 2001, taking account of glacier thinning (and therefore reduction in hydrostatic driving forces) during this period. The bold line passing through curves $B$ shows the backforce reduction consistent with increasing marginal shear stresses caused by the velocity increase.

Longitudinal strain rates were calculated as the gradient $(\partial V / \partial x)$ of measured velocities, and lateral strain rates on the basis of volume continuity. For pre-perturbation values, I assumed steady state at the time of the velocity measurements $\left(\partial H_{\mathrm{i}} / \partial t=A+H_{\mathrm{i}} \varepsilon_{z}-V \partial H_{\mathrm{i}} / \partial x=0\right) ;$ also, $\varepsilon_{z}=$ $-(1+\alpha) \varepsilon_{x}$, so that

$$
\alpha=-1+\left(A-V \partial H_{\mathrm{i}} / \partial x\right) /\left(H_{\mathrm{i}} \varepsilon_{x}\right) .
$$

After the force perturbation, $V$ and $\varepsilon_{x}$ increased by $30 \%$, ice-thickening rate $=\partial H_{\mathrm{i}} / \partial t$, and Equation (3) becomes:

$$
\alpha^{\prime} \sim-1+\frac{\left[A^{\prime}-\frac{\partial H_{\mathrm{i}}}{\partial t}-1.3 V\left(\frac{\partial H_{\mathrm{i}}}{\partial x}+\Delta \frac{\partial H_{\mathrm{i}}}{\partial x}\right)\right]}{\left(1.3 H_{\mathrm{i}}^{\prime} \varepsilon_{x}\right)} .
$$

Equations (3) and (4) were solved along the glacier, using interpolated velocity and ice-thickness estimates, with accumulation rates based on the surface mass balance estimated by Echelmeyer and others (1992), showing $A$ ranging from about $-4 \mathrm{~m}$ of ice $\mathrm{a}^{-1}$ near the grounding line to zero at $1200 \mathrm{~m}$ elevation. I assume $A^{\prime}=1.3 A$ to take account of increasing summer temperatures, but this has little effect on results. The resulting estimates for $\alpha$ and $\alpha^{\prime}$ were then used to calculate corresponding values of $\theta$ and $\theta^{\prime}$.
Equation (A10) can be solved for the change in back pressure:

$$
\Delta P=\left(\varepsilon_{x} / k\right)^{1 / 3}-\left(\varepsilon_{x}^{\prime} / k^{\prime}\right)^{1 / 3}+0.5 \rho_{\mathrm{i}} g \Delta H_{\mathrm{i}} .
$$

Then, with $P=F_{\mathrm{r}} /\left(W H_{\mathrm{i}}\right)$, where $F_{\mathrm{r}}$ is the glacier backforce and $W$ is glacier width (assumed to be unaffected by the change in back pressure), the perturbation in backforce $\Delta F_{\mathrm{r}}$ becomes:

$$
\begin{aligned}
\Delta F_{\mathrm{r}} & =W H_{\mathrm{i}}\left[\Delta P+0.5 \rho_{\mathrm{i}} g \Delta H_{\mathrm{i}}-\left(\varepsilon_{x} / k\right)^{1 / 3} \Delta H_{\mathrm{i}} / H_{\mathrm{i}}\right] \\
& =W H_{\mathrm{i}}\left[\rho_{\mathrm{i}} g \Delta H_{\mathrm{i}}+\left(\varepsilon_{x} / k\right)^{1 / 3}\left(1-\Delta H_{\mathrm{i}} / H_{\mathrm{i}}\right)-\left(\varepsilon_{x}^{\prime} / k^{\prime}\right)^{1 / 3}\right] .
\end{aligned}
$$

This was solved at $5 \mathrm{~km}$ intervals along the glacier to give estimates of the decrease in backforces, $-\Delta F_{\mathrm{r}}$ shown in Figure 2, along with plots of ice thickness, velocity, strain rates and measured thinning rates. For errors of \pm 0.0 .1 in $\Delta \varepsilon_{x} / \varepsilon_{x}, \pm 50 \mathrm{ma}^{-1}$ in velocity (and corresponding $\pm 0.014 \mathrm{a}^{-1}$ in $\left.e_{x}\right), \pm 50 \mathrm{~m}$ in thickness, and $\pm 0.5 \mathrm{~m} \mathrm{a}^{-1}$ in thinning rates, estimated errors in $\Delta F_{\mathrm{r}}$ are also shown in Figure 2. These take no account of errors in $B$ or $W$. Also shown in Figure 2 is the backforce reduction, consistent with a $30 \%$ velocity increase, before the glacier has thinned. This is about $300 \mathrm{GN}$ at the grounding line $(\Delta P \sim 100 \mathrm{kPa})$, 
similar to that estimated (500 GN) from Equation (A18) in the Appendix for the $4 \mathrm{~km}$ retreat of the calving front observed between 1997 and 1998, assuming a marginal shear stress of $100 \mathrm{kPa}$ and seaward ice-tongue thickness of $600 \mathrm{~m}$. But it is far smaller than that required to sustain the velocity increase and ice thinning until 2001, by which time $\Delta H_{\mathrm{i}}$ in Equation (5) had decreased to large negative values.

Continued thinning implies a progressive decrease in backforce at the grounding line, with the decrease rising to $4000 \mathrm{GN}$ in 2001. The glacier's floating ice tongue retreated by $4 \mathrm{~km}$ between 1997 and 1998, and thinned by about $320 \mathrm{~m}$ by 2001, while it readvanced $2 \mathrm{~km}$ (Fig. 1; Thomas and others, 2003). Assuming hydrostatic equilibrium to infer ice thicknesses from measured surface elevations, these changes represent a reduction in area of marginal ice undergoing shear from $S_{\mathrm{m}} \sim 23 \mathrm{~km}^{2}$ in 1997 to approximately $13 \mathrm{~km}^{2}$ in 2001. Then, from Equation (A19) in the Appendix,

$$
\Delta F_{\mathrm{m}}=\tau_{\mathrm{m}}\left[\Delta S_{\mathrm{m}}+\left(S_{\mathrm{m}}+\Delta S_{\mathrm{m}}\right) \Delta V_{\mathrm{c}} / 3 V_{\mathrm{c}}\right],
$$

where $\tau_{\mathrm{m}}$ is the shear stress between the floating tongue and its sides and $\Delta V_{\mathrm{c}} / V_{\mathrm{c}}$ is the fractional increase in ice velocity $(\sim 30 \%)$ between 1997 and 2001. Figure 2d indicates that $\Delta F_{\mathrm{m}} \sim 4000 \mathrm{GN}$ at the grounding line, yielding $\tau_{\mathrm{m}} \sim 350 \mathrm{kPa}$. Substituting this value into Equation (A18) from the Appendix

$$
V_{\mathrm{c}} \sim W\left(\tau_{\mathrm{m}} / B\right)^{3} / 4
$$

with ice-tongue width $W \sim 7 \mathrm{~km}$ and $V \sim 7 \mathrm{~km} \mathrm{a}$, gives a value for the flow parameter $B \sim 220 \mathrm{kPa}^{1 / 3}$, corresponding to an ice temperature of about $-2^{\circ} \mathrm{C}$. Although this estimate is very approximate, it suggests that the combined effects of strain warming and ice-fabric development may have appreciably softened the marginal ice in this region of extremely high shear.

Figure 2 shows the backforce reduction continuing to increase by $900 \mathrm{GN}$ to reach a maximum about $10 \mathrm{~km}$ inland from the grounding line. This can be partly explained by the uphill basal slope in this region, which makes the weight force $\left(F_{\mathrm{w}}\right.$ in Equation $\left.(\mathrm{Al})\right)$ positive (i.e. resisting longitudinal extension): as the glacier thins, $F_{\mathrm{w}}$ decreases, thus decreasing the backforce. The magnitude of the total change between 1997 and 2001 is approximately:

$$
\Delta F_{\mathrm{w}} \sim-\Delta H_{\mathrm{i}} d W \rho_{\mathrm{i}} g \tan \beta
$$

where $\Delta H_{\mathrm{i}}$ is the average total thickness of ice lost between 1997 and 2001 over a glacier width $W$ and distance $d$ upstream from the grounding line, and $\beta$ is the average basal slope over the same region. Distance $d \sim 10 \mathrm{~km}$ and $W \sim 5 \mathrm{~km}$. From Figure $2 \mathrm{a}$ and $\mathrm{b}, \Delta H_{\mathrm{i}} \sim 60 \mathrm{~m}$ and $\tan \beta \sim+0.025$, so that $\Delta F_{\mathrm{w}} \sim-700 \mathrm{GN}$, which is very close to the backforce reduction of $900 \mathrm{GN}$ over the same distance, shown in Figure 2d.

Further inland, the calculated backforce reduction decreases to $800 \mathrm{GN}, 50 \mathrm{~km}$ inland from the grounding line. This may be partly due to the simplifying assumption of constant glacier width. However, although earlier observations (Fastook and others, 1995) show that tributaries join the main glacier trunk, the resulting glacier widening is comparatively minor over the region studied here. Consequently, much of the decrease in backforce reduction probably results from an increase in resisting forces $F_{\mathrm{d}}$ and $F_{\mathrm{m}}$ as glacier speed increased. Assuming it to be solely caused by increasing marginal shear, we can use Equations (6) and (7) to estimate a value of $B \sim 300 \mathrm{kPa} \mathrm{a}^{1 / 3}$ for marginal ice (corresponding to an ice temperature of $-6^{\circ} \mathrm{C}$ ), that best fits the decrease in backforce reduction if $B$ is constant along the glacier margins (Fig. 2d). This is substantially higher than the value calculated above for the margins of the floating ice tongue, but is consistent with upstream decrease in shear strain rates, and therefore in strain softening. Moreover, this estimate represents a maximum value because I have not included the effects of upstream glacier widening nor those of increasing basal shear stresses as velocities increase. Estimates of marginal shear stress from Equation (6) increase from $250 \mathrm{kPa}$ at the inland end of the survey to about $500 \mathrm{kPa} 10 \mathrm{~km}$ inland from the grounding line. Assuming that driving stresses $\left(\tau_{\mathrm{d}} \sim\right.$ product of $\rho_{\mathrm{i}} g H_{\mathrm{i}}$ and surface slope), summed across the $5 \mathrm{~km}$ wide glacier, are balanced by basal $\left(\tau_{\mathrm{b}}\right)$ and marginal $\left(\tau_{\mathrm{m})}\right)$ shear stresses, we can write:

$$
5000 \tau_{\mathrm{d}} \sim 5000 \tau_{\mathrm{b}}+2 H_{\mathrm{i}} \tau_{\mathrm{m}} .
$$

Solution of this equation along the glacier shows $\tau_{\mathrm{b}}$ to be approximately constant at $50 \mathrm{kPa}$, far less than marginal shear stresses, supporting the assumption that stretching of the glacier can be approximated by ice-shelf dynamics.

Calving of most of the remaining ice tongue, in April 2003, should have resulted in additional backforce reduction and continued glacier thinning. Consequently, there is a strong probability of grounding-line retreat over part of the $15-20 \mathrm{~km}$ of glacier bed that slopes uphill in the direction of motion (Fig. 2a). However, ice-surface elevations are far above those representing hydrostatic equilibrium, so substantial retreat would require continued thinning for decades. Moreover, the glacier could establish a new force balance quite rapidly if a new floating tongue forms in the embayment created by retreat of the grounding line of the southern glacier trunk.

\section{CONCLUSIONS}

In the Appendix, I develop a set of equations that explore ramifications for glacier behavior if perturbations in forces that determine longitudinal stresses are swiftly transmitted over long distances up the glacier. Over most of a glacier system, the force driving longitudinal creep is quite small, being the difference between extending hydrostatic and weight forces, and retarding forces associated with shear over the glacier bed and past its sides plus the force needed to push its floating extension seawards. Consequently, small changes in any of these forces can result in large changes in driving force. Rapid perturbations are most probably caused by changes in the retarding forces, such as weakening of the floating extension or increased basal lubrication where the glacier is sliding. In areas with low strain rates, even small changes in the retarding forces can result in large fractional changes in longitudinal strain rates. Fractional strain-rate changes are smaller in areas with large strain rates, but the magnitude of the strain-rate change is larger. Typically, Antarctic glaciers have quite small strain rates, and consequently should show a larger fractional change in longitudinal strain rates (and therefore velocity and mass balance) in response to small force perturbations than more active glaciers in Greenland and temperate regions.

Several effects act to modulate the glacier response to backforce reduction. The analysis presented in the Appendix shows that changing ice thickness acts to balance the perturbation by changing the hydrostatic driving forces as the glacier shifts towards a new thickness profile compatible 
with force balance. The effect of thickness changes on weight forces also reduces the force perturbation if the glacier bed slopes down in the direction of motion, but increases it if the bed slopes upward. Thickening/thinning rates associated with a force perturbation are also affected by changes in ice advection as the glacier velocity changes, and these generally act to reduce the rates of thickness change. Changes in the strain-rate tensor induced by the perturbation also affect glacier response, with greatest impact in regions where $\alpha \sim-2$. Finally, the effects of changing glacier velocities on basal and marginal drag act to reduce the force perturbation.

Application of this force-perturbation analysis to thinning and acceleration of Jakobshavn Isbræ between 1997 and 2001 shows that these changes could have been initiated by calving of $4 \mathrm{~km}$ from the glacier's $14 \mathrm{~km}$ long floating ice tongue in 1997/98. Before 1997, the ice front had advanced and retreated 2 or $3 \mathrm{~km}$ about a position that it had occupied since 1964 (Sohn and others, 1998), indicating that calving-induced backforce reductions during this period were soon balanced as the rapidly moving ice front reoccupied its former position. The recent calving, however, was accompanied by extremely rapid thinning of the floating tongue (averaging about $80 \mathrm{ma}^{-1}$ between 1997 and 2001). This, together with probable flotation of grounded ice rumples within the floating tongue, can probably explain the very large backforce reduction inferred by the force-perturbation analysis at the grounding line between 1997 and 2001. Further inland, backforce reduction is consistent with decreasing weight forces within $10 \mathrm{~km}$ of the grounding line, combined with an increase in lateral drag as velocities increased.

Despite the various causes for negative feedback reviewed above, the glacier has thinned and accelerated dramatically since 1997, and it continues to do so. Indeed, a time series of Landsat images shows calving of much of the remaining floating tongue in April 2003 (Fig. 1) which will further decrease the backforces. Although little additional contribution can be expected from the floating tongue, this major calving event should result in even higher glacier velocities and ice-thinning rates during 2003/04. But without a continued decrease in backforces, these responses should begin to decrease as the glacier runs out of hydrostatic head. A possible cause for future backforce reduction is enhanced basal lubrication associated with drainage to the bed of excessive surface meltwater (Zwally and others, 2002) if summer temperatures continue to be above normal. Without this, ice velocities and thinning rates are likely to peak in 2003/04, and then start to decrease as continued thinning reduces hydrostatic forces. As velocities decrease, however, the negative feedback from increased basal and marginal drag should also decrease, allowing inland values of the force perturbation to increase. Consequently, thinning is likely to continue for several years, with the zone of maximum thinning progressively shifting inland, unless a new floating ice tongue is established in an embayment formed by the retreating grounding line.

\section{ACKNOWLEDGEMENTS}

Much of the material in the Appendix was first presented at the Goldthwaite Lecture at Byrd Polar Research Center, in September 1999, and I particularly want to thankT. Hughes for persuading me to prepare a paper based on this lecture, and for his helpful comments on sequential versions. I thank W. Krabill and his group at NASA/Wallops Flight Facility for acquiring the time series of thickening/thinning rates that revealed the changing behavior of Jakobshavn Isbræ, W. Abdalati for ice-velocity estimations from recent Landsat data, and the many other investigators who have compiled the historical database for this glacier. I also thank E. Frederick and S. Manizade for extensive help with data preparation for my analysis, and the Scientific Editor, T. Scambos, and reviewers J. Fastook and R. Hindmarsh for suggestions that helped to improve the paper. In particular, I thank R. Hindmarsh for stressing the importance of simplifying assumptions that I made in earlier versions of the paper. This work was supported by NASA's ICESat Project.

\section{REFERENGES}

Abdalati, W. and W. B. Krabill. 1999. Calculation of ice velocities in the Jakobshavn Isbræ area using airborne laser altimetry. Remote Sensing Environ., 67(2), 194-204.

Carbonnell, M. and A. Bauer. 1968. Exploitation des couvertures photographiques aériennes répétées du front des glaciers vêlant dans Disko Bugt et Umanak Fjord, juin-juillet, 1964. Medd. Gronl., 173(5).

Clarke, T. S. and K. Echelmeyer. 1996. Seismic-reflection evidence for a deep subglacial trough beneath Jakobshavns Isbræ, West Greenland. F. Glaciol., 42(141), 219-232.

De Angelis, H. and P. Skvarca. 2003. Glacier surge after ice shelf collapse. Science, 299(5612), 1560-1562.

Echelmeyer, K. and W. D. Harrison. 1990. Jakobshavns Isbræ, West Greenland: seasonal variations in velocity - or lack thereof. 7 . Glaciol., 36(122), 82-88.

Echelmeyer, K., W. D. Harrison, T. S. Clarke and C. Benson. 1992. Surficial glaciology of Jakobshavns Isbræ, West Greenland: Part II. Ablation, accumulation and temperature. F. Glaciol., 38(128), 169-181.

Fastook, J. L., H. H. Brecher and T. J. Hughes. 1995. Derived bedrock elevations, strain rates and stresses from measured surface elevations and velocities: Jakobshavns Isbræ, Greenland. f. Glaciol., 41(137), 161-173.

Hindmarsh, R.C.A. 1993. Qualitative dynamics of marine ice sheets. In Peltier, W. R., ed. Ice in the climate system Berlin, etc., Springer-Verlag, 67-99. (NATO ASI Series I: Global Environmental Change 12.)

Hindmarsh, R. C. A. 1996. Stability of ice rises and uncoupled marine ice sheets. Ann. Glaciol., 23, 105-115.

Hughes, T. 1972. Is the West Antartic ice sheet disintegrating? Columbus, OH, Ohio State University. Ice Stream Cooperative Antarctic Project. (IAP Bulletin 1.)

Lingle, C. S., T. J. Hughes and R. C. Kollmeyer. 1981. Tidal flexure of Jakobshavns glacier, West Greenland. 7. Geophys. Res., 86(B5), 3960-3968.

Paterson, W. S. B. 1994. The physics of glaciers. Third edition. Oxford, etc., Elsevier.

Rignot, E., D. G. Vaughan, M. Schmeltz, T. Dupont and D. MacAyeal. 2002. Acceleration of Pine Island and Thwaites Glaciers, West Antarctica. Ann. Glaciol., 34, 189-194.

Shepherd, A., D. Wingham and J. A. Mansley. 2002. Inland thinning of the Amundsen Sea sector, West Antarctica. Geophys. Res. Lett., 29 (10), 1364.

Sohn, H.-G., K. C. Jezek and C. J. van der Veen. 1998. Jakobshavn Glacier, West Greenland: thirty years of spaceborne observations. Geophys. Res. Lett., 25(14), 2699-2702.

Thomas, R. H. 1973a. The creep of ice shelves: interpretation of observed behaviour. 7. Glaciol., 12(64), 55-70.

Thomas, R. H. 1973b. The creep of ice shelves: theory. F. Glaciol., 12(64), 45-53.

Thomas, R. H. and 8 others. 2000. Substantial thinning of a major east Greenland outlet glacier. Geophys. Res. Lett., 27(9), 1291-1294.

Thomas, R. H., W. Abdalati, E. Frederick, W. B. Krabill, S. Manizade and K. Steffen. 2003. Investigation of surface melting and dynamic thinning on Jakobshavn Isbræ, Greenland. F. Glaciol., 49(165), 231-239.

Van der Veen, C.J. 1993. Interpretation of short-time ice-sheet elevation changes inferred from satellite altimetry. Climatic Change, 23(4), 383-405.

Van der Veen, C. J. 1999. Fundamentals of glacier dynamics. Rotterdam, etc., A.A. Balkema Publishers.

Van derVeen, G. J. 2001. Greenland ice sheet response to external forcing. F. Geophys. Res., 106(D24), 34,047-34,058.

Weertman, J. 1957. Deformation of floating ice shelves. F. Glaciol., 3(21), 38-42.

Weertman, J. 1974. Stability of the junction of an ice sheet and an ice shelf. $\mathcal{F}$. Glaciol., 13(67), 3-11.

Weidick, A. 1995. Greenland, with a section on Landsat images of Greenland by Richard S. Williams, Jr. and Jane G. Ferrigno. U.S. Geol. Surv. Prof. Pap. 1386-C.

Zwally, H. J., W. Abdalati, T. Herring, K. Larson, J. Saba and K. Steffen. 
2002. Surface melt-induced acceleration of Greenland ice-sheet flow. Science, 297(5579), 218-222.

\section{APPENDIX}

\section{EFFECT OF FORGE PERTURBATIONS ON LONGI- TUDINAL STRAIN RATES}

\section{A1. Force balance}

Conventionally, ice velocity is expressed as a relationship between local driving forces and ice material properties and/or conditions at the glacier bed. This tends to focus attention on shearing stresses determined by surface slope and ice thickness. But ice velocity is also the sum effect of longitudinal strain, which is determined by longitudinal stresses. My purpose here is to pursue this view of velocity in order to develop equations relating perturbations in longitudinal forces with their effects on strain rates and therefore velocity. I assume that longitudinal forces and their perturbations are transmitted up the glacier, and that longitudinal creep is determined by dynamics similar to those governing ice-shelf behavior. This means that estimated glacier responses probably represent upper limits, and comparison of these estimates with observations will help assess the viability of this approximation.

The approach adopted here is similar to that of Weertman (1957) and Thomas (1973a) in early analyses of ice-shelf spreading. For a two-dimensional ice sheet, with zero basal slope transverse to the flow direction, I take curvilinear axes with $x$ in the flow direction along the bed smoothed over several (10-20) times the ice thickness, $y$ in the transverse horizontal direction, and $z$ perpendicular to the smoothed ice bed (Fig. 3). At any point at distance $x$ along an ice-sheet discharge glacier or ice stream (hereafter referred to as glacier, including any floating extension) of width $W$, the tensile force $\left(F_{\mathrm{E}}(x)\right)$ for spreading the glacier in the direction of motion is:

$$
\begin{aligned}
F_{\mathrm{E}}(x)= & \int_{-W / 2}^{W / 2} 0.5 \rho_{\mathrm{i}} g H H_{\mathrm{i}} \mathrm{d} y \\
& -\int_{x}^{L}\left[\int_{-W / 2}^{W / 2}\left(\rho_{\mathrm{i}} g H_{\mathrm{i}} \tan \beta+\tau_{\mathrm{b}}\right) \mathrm{d} y-\int_{0}^{H} \tau_{\mathrm{m}} \mathrm{d} z\right] \mathrm{d} x \\
& -\int_{-W / 2}^{W / 2} 0.5 \rho_{\mathrm{w}} g D_{\mathrm{w}}^{2} \mathrm{~d} y-F_{\mathrm{B}}
\end{aligned}
$$

or:

$$
F_{\mathrm{E}}(x)=F_{\mathrm{h}}(x)-F_{\mathrm{w}}(x)-F_{\mathrm{d}}(x)-F_{\mathrm{m}}(x)-F_{\mathrm{g}}-F_{\mathrm{b}} .
$$

The first term on the righthand side is the hydrostatic force $\left(F_{\mathrm{h}}\right)$ with $\rho_{\mathrm{i}}$ ice density, $g$ acceleration due to gravity, $H_{\mathrm{i}}$ vertical ice thickness, and $H$ the value of $z$ at the surface. The second term is the compressive force $\left(F_{\mathrm{w}}\right)$ associated with the net upstream component of weight forces acting on the glacier as it flows over a basal slope $\beta$ with respect to true horizontal, taken positive uphill in the direction of motion. The remaining terms are the resisting force $\left(F_{\mathrm{d}}\right)$ caused by basal drag $\left(\tau_{\mathrm{b}}\right)$, and that $\left(F_{\mathrm{m}}\right)$ caused by marginal shear $\left(\tau_{\mathrm{m}}\right)$ of the glacier past its sides, the backforce $\left(F_{\mathrm{g}}\right)$ exerted

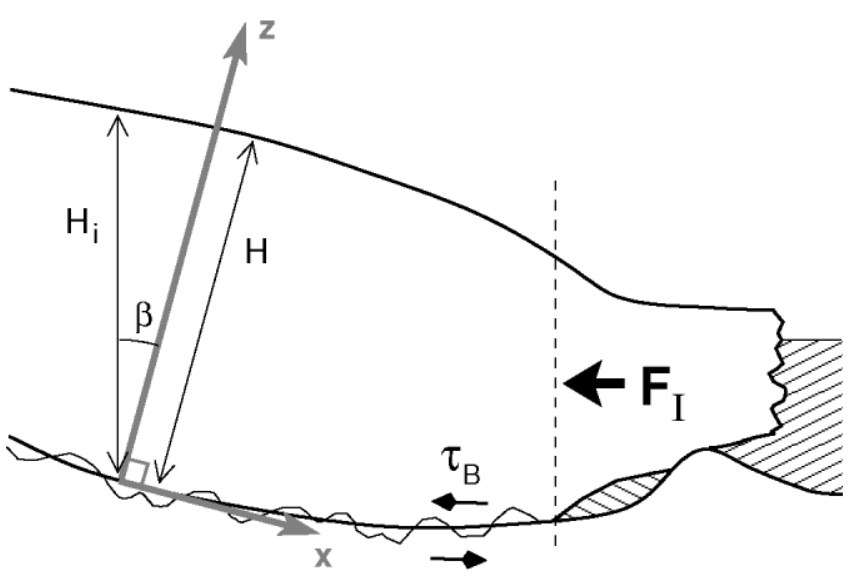

Fig. 3. The coordinate system used here.

on the glacier at its grounding line (at $x=L$ ) by depth $D_{\mathrm{w}}$ of sea or lake water with density $\rho_{\mathrm{w}}$, and additional backforce $\left(F_{\mathrm{b}}\right)$, transmitted to the grounding line by any floating extension, associated with areas where this extension runs aground or shears past its sides.

Equation $(\mathrm{Al})$ can be abbreviated to:

$$
F_{\mathrm{E}}(x)=F_{\mathrm{h}}(x)-F_{\mathrm{r}}(x),
$$

with $F_{\mathrm{r}}(x)$ the resisting forces including for convenience, $F_{\mathrm{w}}$ which is generally negative and therefore tensile. Assuming resistive forces are distributed evenly over the glacier crosssection $(S(x))$, the longitudinal tensile stress is:

$$
\sigma_{\mathrm{E}}(x)=0.5 \rho_{\mathrm{i}} g H_{\mathrm{i}}(x)-F_{\mathrm{r}}(x) / S(x) .
$$

Assuming that the glacier moves primarily by stretching, with little shear except near the bed and ice margins, the longitudinal creep rate can be expressed in a form similar to that for an ice shelf:

$$
\varepsilon_{x}=k\left(\sigma_{\mathrm{E}}\right)^{n}
$$

where $n \sim 3, k=\theta / B^{n}, \theta=\left(1+\alpha+\alpha^{2}+\gamma^{2}\right)^{(n-1) / 2} /(2+\alpha)^{n}$, with $\alpha=\epsilon_{y} / \epsilon_{x}$, and $\gamma=\epsilon_{x y} / \epsilon_{x}$, taking account of lateral $\left(\epsilon_{y}\right)$ and shear $\left(\epsilon_{x y}\right)$ strain rates, and $B$ is the ice-hardness parameter averaged over the glacier cross-section at $x$ (Thomas, 1973a). Note that I adopt a temperature dependence of $B$ inferred from table 5.2 in Paterson (1994).

The assumptions here limit application to wide, thick glaciers, where most shear takes place near the bed or ice margins. Within such glaciers, most of the ice moves seaward as a large slab that is stretching/compressing in the flow direction and diverging/converging laterally. Whatever shear does occur within the slab serves to increase the effective shear stress, thereby softening the ice.

Equations (A2-A4) yield:

$$
\varepsilon_{x}(x) \sim k(x)\left(0.5 \phi(x) \rho_{\mathrm{i}} g H_{\mathrm{i}}(x)\right)^{n},
$$

where $\phi(x)\left(=F_{\mathrm{E}}(x) / F_{\mathrm{h}}(x)\right)$ is the fraction of the hydrostatic force available to stretch the glacier. $\phi$ is generally small, reaching a maximum of about $10 \%$ for a freely floating ice shelf, but can be larger for regions of thick, grounded ice if resistive forces are suddenly reduced, such as during a glacier surge. Generally, however, $\phi$ is far smaller for grounded ice that is anywhere near steady state. Otherwise creep thinning would become far too large to be balanced 


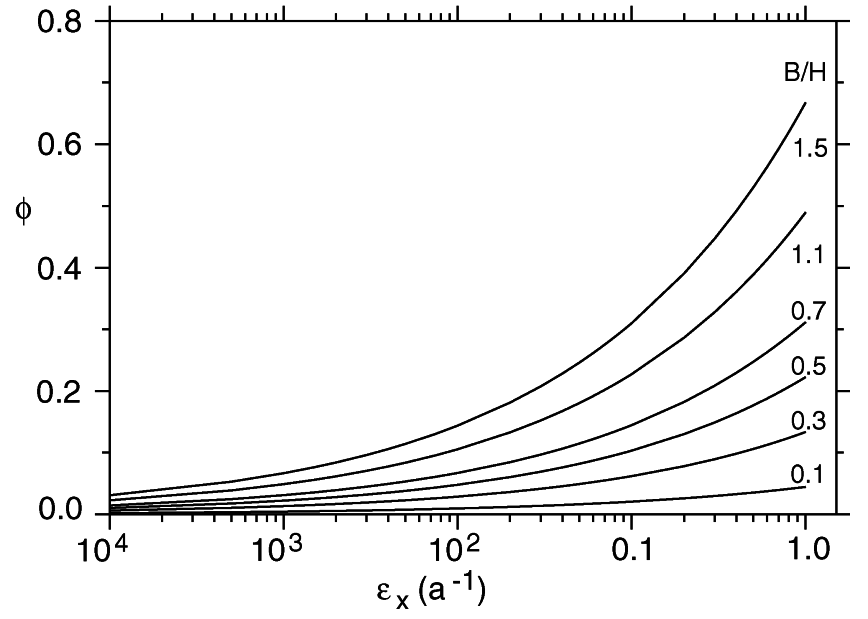

Fig. 4. A plot of the fraction ( $\phi$ ) of total driving force available to stretch the glacier, vs longitudinal creep rate, for different values of $\mathrm{B} / \mathrm{H}$ (in $\left.\mathrm{kPa} \mathrm{m} \mathrm{m}^{-1} a^{1 / 3}\right)$. A typical range for $B$ is 400-600 $\mathrm{kPa} \mathrm{a}^{1 / 3}$, corresponding to ice temperatures between about $-10^{\circ}$ and $-21^{\circ} \mathrm{C}$. Thus $\mathrm{B} / \mathrm{H}=1.5 \mathrm{kPa} \mathrm{m}^{-1} \mathrm{a}^{1 / 3}$ corresponds to $H=267-400 \mathrm{~m} ; \mathrm{B} / \mathrm{H}=0.1 \mathrm{kPa} \mathrm{m}^{-1} a^{1 / 3}$ corresponds to $H=4000-6000 \mathrm{~m}$. Strain rates along much of a glacier are $<0.01 a^{-1}$, implying $\phi<0.15$.

by local and upstream accumulation. An estimate of the magnitude of $\phi$ can be obtained by inverting Equation (A5):

$$
\phi(x) \sim 2\left(\varepsilon_{x}(x) / k(x)\right)^{1 / n} / \rho_{\mathrm{i}} g H_{\mathrm{i}}(x)
$$

and solving with $n=3$, using observations of glacier geometry, strain rates and temperatures. For example, with zero transverse divergence/convergence (so that $\phi=1 / 8$ ), Equation (A6) becomes:

$$
\phi=4 B \varepsilon_{x}^{1 / 3} /\left(\rho_{\mathrm{i}} g H_{\mathrm{i}}\right)
$$

and we can plot $\phi$ vs $\epsilon_{x}$ for different values of $H_{\mathrm{i}}$ and $B$ (Fig. 4). Clearly, the longitudinal creep rate is very sensitive to the value of $\phi$, which in turn is determined by the difference between two very large forces, so that small changes in either of these forces can have a large effect on $\phi$, and an even larger one on creep rates. The tensile forces are difficult to change rapidly, so the longitudinal creep rate can be very sensitive to quite small changes in the resistive forces. The most likely causes of such changes are major changes in basal lubrication or in ice-shelf backforces.

\section{A2. Perturbations}

Combining Equations (A3) and (A4), and setting $n=3$ :

$$
\varepsilon_{x}(x) \sim k(x)\left(0.5 \rho_{\mathrm{i}} g H_{\mathrm{i}}(x)-P(x)\right)^{3},
$$

where $P(x)\left(=F_{\mathrm{r}}(x) / S(x)\right)$ is the back pressure, comprising the various terms in Equation (1). Following a perturbation $(\Delta)$ in the forces acting on the glacier, this becomes:

$$
\begin{aligned}
\varepsilon_{x}^{\prime}(x) \sim & k^{\prime}(x)\left(0.5 \rho_{\mathrm{i}} g H_{\mathrm{i}}(x)-\Delta P(x)\right. \\
& \left.+0.5 \rho_{\mathrm{i}} g \Delta H_{i}(x)-P(x)\right)^{3}
\end{aligned}
$$

where post-perturbation values are primed. Then, using Equation (A8):

$$
\Delta \varepsilon_{x} / \varepsilon_{x}=k^{\prime}\left[\left(\varepsilon_{x} / k\right)^{1 / 3}+0.5 \rho_{\mathrm{i}} g \Delta H_{\mathrm{i}}-\Delta P\right]^{3} / \varepsilon_{x}-1 .
$$

Hydrostatic forces and the flow parameter $(B)$ are unlikely
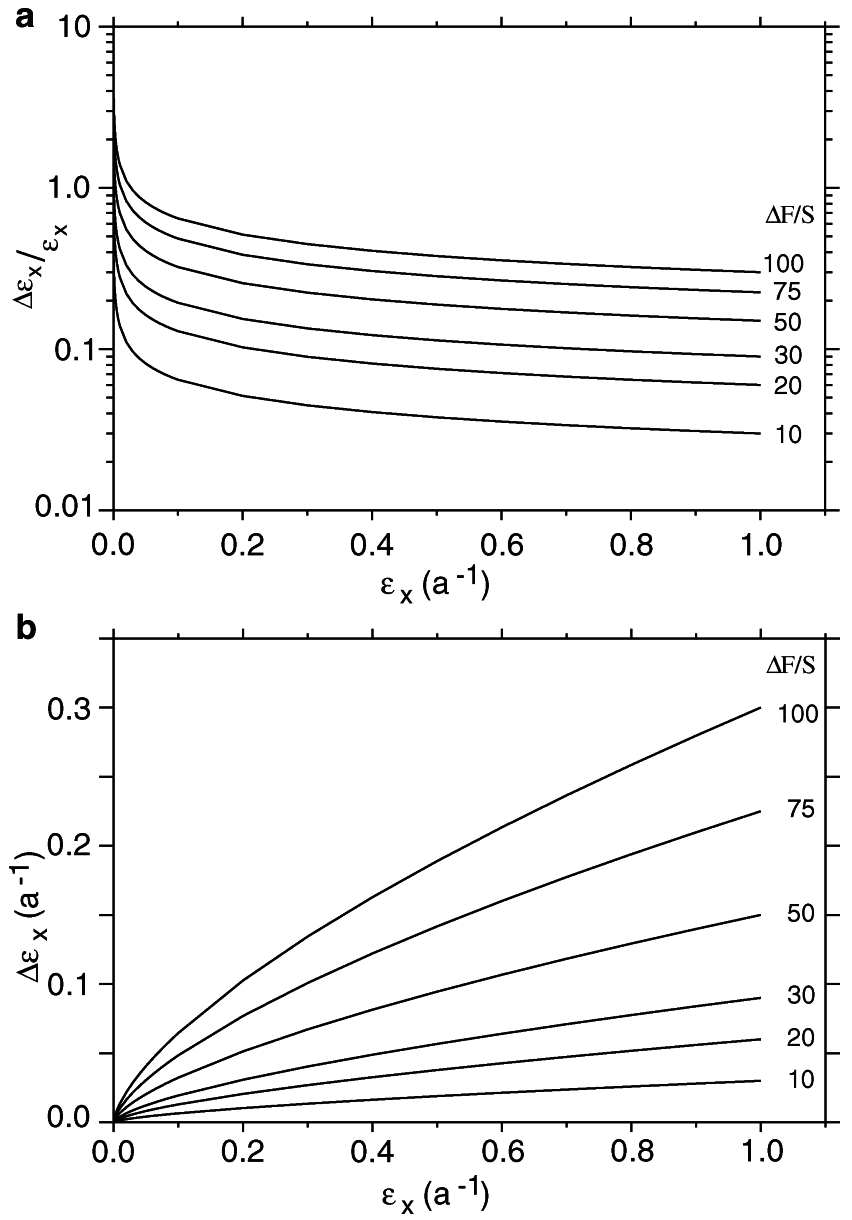

Fig. 5. Plots of the fractional increase in longitudinal strain rates ( $a$ ), and the strain-rate increase ( $b$ ), against the preperturbation strain rate, for various values of the perturbation in longitudinal stresses $(\Delta F / S$ in $k P a)$.

to change rapidly, so perturbation is most probably caused initially by a change in resisting forces responsible for the back pressure $(P)$. Then, with $B=500 \mathrm{kPa}^{1 / 3}$ (equivalent to an ice temperature of approximately $-16^{\circ} \mathrm{G}$ ), zero lateral convergence/divergence $(\phi=1 / 8)$ and $k=k^{\prime}$,

$$
\Delta \varepsilon_{x} / \varepsilon_{x}=\left(\varepsilon_{x}^{1 / 3}-0.001 \Delta P\right)^{3} / \varepsilon_{x}-1
$$

with $\epsilon_{x}$ expressed in $\mathrm{a}^{-1}$ and $\Delta P$ in $\mathrm{kPa}$. Fractional strainrate increase $\left(\Delta_{x} / \epsilon_{x}\right)$ and the strain-rate increase $\left(\Delta \epsilon_{x}\right)$ are plotted in Figure $5 \mathrm{a}$ and $\mathrm{b}$ respectively against the preperturbation longitudinal strain rate $\left(\epsilon_{x}\right)$ for various values of the stress release $(-\Delta P)$. For a given force perturbation, the fractional increase in strain rates decreases, but the strain-rate perturbation increases, with increasing $\epsilon_{x}$. For example, a $10 \%$ fractional increase in $\epsilon_{x}$ requires a stress release of about $30 \mathrm{kPa}$ for $\epsilon_{x}=0.7 \mathrm{a}^{-1}$, but only about half this for $\epsilon_{x}=0.1 \mathrm{a}^{-1}$. If the stress release is felt over most of the more active regions of the glacier, the strain-rate increase results in a similar fractional velocity increase. Consequently, we should expect glaciers with small longitudinal strain rates (typically found in Antarctica) to show a bigger fractional velocity increase to small force perturbations than those with high longitudinal creep rates (typical of Greenland and temperate regions). 
Thickness changes can be estimated by invoking volume-continuity requirements that:

$$
\varepsilon_{z}=-(1+\alpha) \varepsilon_{x} \sim\left(\partial H_{\mathrm{i}} / \partial t+V \partial H_{\mathrm{i}} / \partial x-A\right) / H_{\mathrm{i}},
$$

where $A$ is accumulation rate expressed as a depth of ice per unit time, and $V$ is vertically averaged ice velocity. Assuming that the glacier is in steady state $(\partial H / \partial t=0)$ before the perturbation, at time $\Delta T$ after a force perturbation has been applied, the rate of thickness change is:

$$
\begin{gathered}
\partial H_{\mathrm{i}} / \partial t \sim \Delta A-(1+\alpha)\left(H_{\mathrm{i}} \Delta \varepsilon_{x}+\varepsilon_{x} \partial H_{\mathrm{i}}\right)-H_{\mathrm{i}} \varepsilon_{x} \Delta \alpha \\
-V \Delta\left(\partial H_{\mathrm{i}} / \partial x\right)-\Delta V \partial H_{\mathrm{i}} / \partial x,
\end{gathered}
$$

where the prefix $\Delta$ refers to the change in a quantity during $\Delta T$. Then, using Equation (A10),

$$
\begin{aligned}
\partial H_{\mathrm{i}} / \partial t \sim & \Delta A-(1+\alpha)\left(H _ { \mathrm { i } } \left\{k ^ { \prime } \left[\left(\varepsilon_{x} / k\right)^{1 / 3}\right.\right.\right. \\
& \left.\left.\left.+0.5 \rho_{\mathrm{i}} g \Delta H_{\mathrm{i}}-\Delta P\right]^{3}-\varepsilon_{x}\right\}+\varepsilon_{x} \Delta H_{\mathrm{i}}\right) \\
& -H_{\mathrm{i}} \varepsilon_{x} \Delta \alpha-V \Delta\left(\partial H_{\mathrm{i}} / \partial x\right)-\Delta V \partial H_{\mathrm{i}} / \partial x .
\end{aligned}
$$

\section{A3. Feedback effects}

Equation (A10) shows the change in longitudinal strain rates to be strongly determined by the value of $k^{\prime}$ $\left(=\theta^{\prime} / B^{\prime 3}\right)$. Although $B$ should change only slowly after a force perturbation, changes in $\epsilon_{x}$ are likely to affect the value of $\alpha$ and hence also $\theta$. For small shear strain rates, $\partial \theta / \partial \alpha \sim-(\alpha-1)^{2} /(2+\alpha)^{4}$. Consequently, values of $\theta^{\prime}$ and $k$ are extremely sensitive to $\alpha$ in areas where $\alpha$ is close to -2 , which is most likely where glacier flow is longitudinally compressive and laterally divergent. In such areas, small changes in the shape of the strain-rate tensor have a dominant impact on the glacier response to a perturbation, and results from Equation (A10) become sensitive to small measurement errors. Fortunately, such areas are not common. Equation (A10) also shows that the strain-rate response to a perturbation will decrease as the thickness response $\left(\Delta H_{i}\right)$ increases. This means, for example, that following a sudden reduction in backforce, strain rates and glacier velocities should increase swiftly to a maximum, and then decrease as associated glacier thinning increases the magnitude of $\Delta H_{i}$, and the glacier shifts towards a new thickness profile.

From Equation (Al), the total backforce is

$$
F_{\mathrm{r}}(x)=F_{\mathrm{w}}(x)+F_{\mathrm{d}}(x)+F_{\mathrm{m}}(x)+F_{\mathrm{g}}+F_{\mathrm{b}} .
$$

Following a change in any of these forces, others may be affected by resulting changes in the glacier. Thus, a change in the ice-shelf backforce $\left(F_{\mathrm{b}}\right)$ might cause changes in glacier thickness and velocity. In turn, these changes are likely to alter some or all of the other terms. Changing thickness will alter $F_{\mathrm{w}}$ and the position of the grounding line, and therefore $F_{\mathrm{g}}$, unless the glacier bed is horizontal, with effects on backforce perturbation dependent on the sign and magnitude of basal slope. Changing velocity will alter $F_{\mathrm{d}}$ and $F_{\mathrm{m}}$, reducing the backforce perturbation to an extent determined by relationships between velocity and basal and marginal drag. For instance, upstream from the seaward part of a fast-moving glacier, backforce associated with marginal $\operatorname{shear}\left(\tau_{\mathrm{m}}\right)$ is

$$
F_{\mathrm{m}} \cong S_{\mathrm{m}} \tau_{\mathrm{m}}
$$

where $S_{\mathrm{m}}$ is the area of marginal ice undergoing shear.
Changes in either of the terms on the righthand side of this equation result in backforce changes given by:

$$
\Delta F_{\mathrm{m}} \cong\left(S_{\mathrm{m}}+\Delta S_{\mathrm{m}}\right) \Delta \tau_{\mathrm{m}}+\Delta S_{\mathrm{m}} \tau_{\mathrm{m}}
$$

Approximating center-line velocity $\left(V_{\mathrm{c}}\right)$ as

$$
V_{\mathrm{c}} \cong W\left(\tau_{\mathrm{m}} / B\right)^{3} / 4
$$

(e.g. van der Veen, 1999, p. 125-127), a velocity change by $\Delta V_{\mathrm{c}}$ implies a change in marginal shear stress given by:

$$
\Delta \tau_{\mathrm{m}} / \tau_{\mathrm{m}} \cong \Delta V_{\mathrm{c}} / 3 V_{\mathrm{c}}
$$

assuming no change in $W$ or $B$. Equation (A17) then becomes:

$$
\Delta F_{\mathrm{m}} \cong \tau_{\mathrm{m}}\left[\Delta S_{\mathrm{m}}+\left(S_{\mathrm{m}}+\Delta S_{\mathrm{m}}\right) \Delta V_{\mathrm{c}} / 3 V_{\mathrm{c}}\right] .
$$

Thus, calving from an embayed ice shelf would reduce $S_{\mathrm{m}}$ and $F_{\mathrm{m}}$, the resulting velocity increase would then increase $F_{\mathrm{m}}$, but any associated glacier thinning would decrease $F_{\mathrm{m}}$ by reducing $S_{\mathrm{m}}$.

In addition to feedback effects on the strain-rate response, changes in ice thickness are also affected by the terms in Equation (A14) underlined here:

$$
\begin{aligned}
\partial H_{\mathrm{i}} / \partial t \sim & \underline{\Delta}-(1+\alpha)\left(H _ { \mathrm { i } } \left\{k ^ { \prime } \left[\left(\varepsilon_{x} / k\right)^{1 / 3}\right.\right.\right. \\
& \left.\left.\left.+0.5 \rho_{\mathrm{i}} g \Delta H_{\mathrm{i}}-\Delta P\right]^{3}-\varepsilon_{x}\right\}+\underline{\varepsilon_{x} \Delta H_{\mathrm{i}}}\right) \\
& \left.-\underline{H_{\mathrm{i}} \varepsilon_{x} \Delta \alpha}-\underline{V \Delta\left(\partial H_{\mathrm{i}} / \partial x\right.}\right)-\underline{\Delta V H_{\mathrm{i}} / \partial x} .
\end{aligned}
$$

For some time after the force perturbation, the largest of these terms is likely to be the change in ice advection $\left(\Delta V \partial H_{i} / \partial x\right)$ resulting from the velocity change. This will generally reduce the magnitude $\partial H_{i} / \partial t$ because $\partial H_{i} / \partial x$ is most commonly negative. Changing thickness and thickness slope should also provide negative feedback. Because of these various feedback effects, it is possible for parts of a glacier to thicken while longitudinal strain rates and discharge velocities increase.

\section{A4. Perturbation scenarios}

In order to estimate the magnitude of force perturbations likely to affect glaciers, I shall consider two simple cases: thinning of the floating extension of a glacier, and reduction in basal drag within part of its lower reaches. In each case, I assume the glacier to be flowing over a horizontal bed, and glacier width at distance $x$ along the glacier is $W(x)$.

\section{A4.1. Ice-shelf weakening}

The glacier is assumed to flow into a floating tongue, or ice shelf, containing locally grounded ice rises (with zero velocity at centers) and ice rumples (where the ice is pushed over the local grounding). If one of these is lost (i.e. the ice floats free from local grounding), the change in backforce is:

$$
\Delta F_{\mathrm{IR} 1}=-\left(w H_{\mathrm{u}} \tau_{\mathrm{c}}+2 d H_{\mathrm{s}} \tau_{\mathrm{s}}\right)
$$

for an ice rise, and

$$
\Delta F_{\mathrm{IR} 2}=-w d \tau_{\mathrm{b}}
$$

for ice rumples, where $w$ is the width of the ice rise/rumples transverse to ice motion, $d$ is the length along the flow direction $H_{\mathrm{u}}$ is the average thickness of floating ice immediately upstream of the ice rise, $\tau_{\mathrm{c}}$ is the average compressive stress in this same area $H_{\mathrm{s}}$ is the average thickness of floating ice along $d, \tau_{\mathrm{s}}$ is the average shear stress between floating and grounded ice in this same area, and $\tau_{\mathrm{b}}$ is the average basal shear stress for the ice rumples. Values of $\tau_{\mathrm{c}}$ can be far higher 
than usually associated with basal and marginal shear stresses, so I assume $\tau_{\mathrm{s}}=\tau_{\mathrm{b}}=\tau_{\mathrm{c}} / R=100 \mathrm{kPa}$, and that $H_{\mathrm{u}}=H_{\mathrm{s}}$. Then,

$$
\begin{aligned}
& \Delta F_{\mathrm{IR} 1} \sim-10^{5} H_{\mathrm{u}}(R w+2 d) \mathrm{N} \\
& \Delta F_{\mathrm{IR} 2}=-10^{5} w d \mathrm{~N} .
\end{aligned}
$$

Typically, $H_{\mathrm{u}} \sim 300-1000 \mathrm{~m}, R$ can be as much as 5 or more (Thomas, 1973b) and ice rises/rumples likely to float free over short time periods are comparatively small (say $w \sim d=0.5-1 \mathrm{~km}$ ). These values give a range for $\Delta F_{\mathrm{IR}}$ of about -50 to $-700 \mathrm{GN}$ for an ice rise and -30 to $-100 \mathrm{GN}$ for ice rumples.

Ice-shelf thinning (by $\Delta H_{\mathrm{IS}}$ ), or retreat (by $\Delta D$ ) of the side area of an ice shelf undergoing marginal shear $\left(\tau_{\mathrm{s}}\right)$, yields a backforce reduction of:

$$
\begin{aligned}
& \Delta F_{\text {IS }}=-2\left(\Delta D H_{\text {IS }}+D \Delta H_{\text {IS }}\right) \tau_{\mathrm{s}} \\
& \sim-2 \times 10^{5}\left(\Delta D / D+\Delta H_{\text {IS }} / H_{\text {IS }}\right) D H_{\text {IS }} \mathrm{N} \\
& \quad \text { for } \tau_{\mathrm{s}}=100 \mathrm{kPa},
\end{aligned}
$$

where $D$ is the ice-shelf length and $H_{\mathrm{IS}}$ is average thickness at its sides. Thus for a $1 \%$ reduction in length or thickness, $\Delta F_{\text {IS }} \sim-2000 D H_{\text {IS N }}$. For example, the Pine Island ice shelf has $D \sim 60 \mathrm{~km}$ and $H_{\mathrm{IS}} \sim 500 \mathrm{~m}$, yielding $\Delta F_{\mathrm{IS}} \sim 60 \mathrm{GN}$ for a $1 \%$ reduction in length or thickness.

A4.2. Lubrication of the glacier bed

Here, I consider the simple case of an area $\left(S_{\mathrm{b}}\right)$ at the base of the glacier lubricated, for instance, by rapid drainage of a surface lake, to reduce basal shear stress locally by $\Delta \tau_{\mathrm{b}}$. Upstream from this region, the backforce per unit width is then changed by:

$$
\Delta F_{\mathrm{d}}=-S_{\mathrm{b}} \Delta \tau_{\mathrm{b}}
$$

Here, $\Delta \tau_{\mathrm{b}}$ may be considerably less than $100 \mathrm{kPa}$ because such lubrication is most likely to occur in areas where the basal shear stress is already quite small. For $\Delta \tau_{\mathrm{b}}=10 \mathrm{kPa}$, values of $\Delta F_{\mathrm{d}}$ ranging from -50 to $-700 \mathrm{GN}$ would require $S_{\mathrm{b}}=5-70 \mathrm{~km}^{2}$.

These estimates suggest that a backforce reduction of a few tenths of a GN would be associated with quite small changes in downstream ice shelves or in the basal lubrication of a glacier. In order to translate such perturbations into their effect on glacier behavior, a value of $\Delta F=-100 \mathrm{GN}$ distributed over a glacier cross-section $(S)$ of $5 \mathrm{~km}^{2}$ (similar to Jakobshavn Isbræ) and over $50 \mathrm{~km}^{2}$ (similar to Pine Island Glacier) represents a stress reduction $(\Delta F / S$ in Fig. 5) of 20 and $2 \mathrm{kPa}$ respectively. Longitudinal strain rates on the two glaciers are typically a few tenths and a few hundredths per year respectively (Echelmeyer and Harrison, 1990; personal communication from E. Rignot, 2002), corresponding in Figure 5 to a fractional increase in strain rates of about $10 \%$ for Jakobshavn Isbræ and $5 \%$ for Pine Island Glacier. 